\section{Modern approaches to assessment of PAHs bioavailability in soil for environmental toxicology research}

\author{
Krektun, B. V. ${ }^{1}$ - Snitynskiy, V. V. ${ }^{1}-$ \\ Maliszewska-Kordybach, B. $^{2}-$ Smreczak, B. ${ }^{2}$ \\ ${ }^{1}$ Lviv National Agrarian University, Lviv, Ukraine \\ ${ }^{2}$ Institute of Soil Science and Plant Cultivation, Pulawy, Poland \\ bohdan.kbv@ukr.net
}

\section{SUMMARY}

The efficiency of TENAX beads sorption method enabling to separate the bioavailable fraction of PAHs in the soil has been estimated. Due to the method the PAHs effects on soil biota have been explored. Laboratory investigations have ascertained possibility of application of TENAX beads sorption for soil quality assessment.

Keywords: polycyclic aromatic hydrocarbons, bioavailability, ecotoxicity, soil

A crucial problem in modern methodology of environmental quality assessment is the possibility of improving existing methods and developing new ones concerning the polycyclic aromatic hydrocarbon (PAH) concentration measurements in different types of soil (Smreczak and Maliszewska-Kordybach, 2003; Smreczak et al., 2005; Snitynskiy, 2008).

Polycyclic aromatic hydrocarbons belong to a group of widely spread in the environment organic substances, possessing strictly defined ecotoxicological effects. PAHs in the soil are capable not only of suppressing some chains of metabolic processes in organisms of plants, mezofauna and microbes, but also undergo biotransformation being involved in oxidative processes of other metabolic chains of particular species of soil organisms (Bosma and Harms, 1996; Alexander, 2000).

Generally accepted methods of environmental hazard analysis of those pollutants do not properly show the ratio of their biological activity to their concentration (Jensen, 1995; Smreczak and Harmsen, 2001; Alexander, 2000). Therefore the comparison of their concentration with sanitary indexes does not take into consideration the multifold effects of toxicants on different components of the ecosystem. Particularly, the total content of PAHs in soil does not represent the real quantities responsible for the harmful effect, potential quantities undergoing biotransformation under biota effects, and the PAHs tightly bound inside soil particles. In this regard, the development of polycyclic aromatic hydrocarbon bioavailability evaluation techniques is of special interest.

The bioavailability of PAHs in soil organisms is an important characteristic which enables us to determine the potential of organic pollutant degradation in soil, the rate of their accumulation and their ecotoxicological effects, the quantities of "aged" pollutants inaccessible to the processes of biodegradation (Kelsey, 1997; Alexander, 2000).

PAHs are nonionic organic compounds primarily sorbed by the lipophilic fraction of soil organic matter matter (Jones et al., 1996; Karickhoff, 1984; Maliszewska-
Kordybach, 1995, 1998; Sims and Oveercash, 1983; Wild and Jones, 1996). The binding inside the organic matrix considerably decreases the transfer of PAHs into aqueous and gaseous phases and thus retards the migration of $\mathrm{PAH}$ bioavailable fractions in the soil. Both the solubility of PAHs and the sorption peculiarities of the soil were considered to be the key features determining the bioavailability of PAHs and their ability to migrate in the soil environment. These properties determine the distribution of molecules of the compounds between the soil solution and the particles (Sims and Oveercash, 1983; Wild and Jones, 1996). These factors to a grate extent define the particular part of the total content of pollutants actually affecting the metabolic processes in soil organisms.

The comparative analysis of different methods allowing to separate the bio-available fraction of PAHs in soils has been carried out (Smreczak et al. 2005; Cornelissen et al., 2000; Cornelissen et al., 2001). In particular, methods based on the biomimetic approach, using polymeric resins and others sorbents, have shown appropriate efficiency while researching the PAHs effects on soil biota (Cornelissen et al., 2000; Smreczak et al., 2005; Snitynskiy, 2008).

Among the methods of PAHs bioavailability estimation in soil, the TENAX- method has proved to be quite efficient (Cornelissen et al., 2000; Smreczak et al., 2005; Snitynskiy, 2008). Polyether carbon resin type of TENAX is capable of adsorbing PAHs on their surface as well as within the pores. Solid-phase extraction with TENAX beads is widely employed and described in scientific literature in studying the processes of PAHs biodegradation (Xing and Pignatello, 1997; Cornelissen et al., 2000, 2001). In our investigation we managed to prove the efficiency of solid-phase extraction with TENAX beads in evaluating the ecotoxicological effects of these compounds. Namely, the ecotoxicological effects of bioavailable fractions of phenantrene and pyrene extracted by means of TENAX beads were described.

Bioavailable fractions of two model PAH compounds (pyrene and phenantrene) were determined in freshly contaminated soil.

Heavy loam $(\% \mathrm{C}=3,5 ; \mathrm{pHKCl}=7,3)$ was used in the laboratory study. Soil samples were air-dried and sieved prior to use. Plastic pots were filled with dry soil, soil samples were watered up to $40 \%$ of full water capacity and preincubated in darkness at $200{ }^{\circ} \mathrm{C}$. After contamination of soils with pyrene and phenantrene at the level of: $1,10,100,500,1000 \mathrm{mg} \mathrm{kg}^{-1}$, the soil samples were incubated for the next 7 day period.

The bioavailable fraction of PAH compounds was determined using Tenax TA beads as a PAH adsorbent 
from the aqueous phase according procedure described by Cornelissen $(2000,2001)$. The concentration of PAHs was determined via gas-chromatography. The response of soil microorganisms to PAH contamination was evaluated at the activity level. The potential of nitrification was determined after 2 and 168 hours of incubation.

It was observed that the increase of concentration of phenantrene in the freshly contaminated soil causes the augmentation of bioavailable fraction size to $40 \%$ compared to the total concentration of PAHs in the experimental soil. It was shown that the content of the organic carbon in the soil is an important factor affecting the extractability of phenantrene from the contaminated soil. Due to a considerable affinity of the soil organic matter to this type of nonpolar organic substances, the high content of organic carbon can significantly decrease the PAH bioavailability and slow down their circulation in the soil environment between the soil water and the air. Furthermore, a correlation was established between the content of bioavailable fraction of phenantrene and pyrene and nitrification potential of soils.

Our investigation ascertained the efficiency of evaluating the ecotoxicological effects of extracted by means of TENAX beads phenantrene and pyrene bioavailable fractions. It enables us to use this method in various explorations of ecotoxical properties of PAHs bioavailable concentration in soil.

The present research appears to be an important step towards the elaboration of methodological approaches and practical guidelines focusing on the environmental protection and ecologically safe agricultural production.

\section{REFERENCES}

Alexander, M. (2000): Critical review: Aging, bioavailability, and overestimation of risk from environmental pollutants. Eviron. Sci. Technol. 20: 4259-4265.

Bosma, T.-Harms, H. (1996.):Bioavailability of organic pollutant. EAWAG News. V. 40E. 28-31.

Cornelissen, G.-Rigterink, H.--van Noort, P. C. M.-Govers, H. A. J. (2000): Slowly and very slowly desorbing organic compounds in sediments exhibit Langmuir-type sorption. Environ. Toxicol. Chem. 19: 1532-1540.

Cornelissen, G.-Hulscher, Th. E. M.-Rigterink, H.-Vrind, B. A.-van Noort, P. C. M. (2001): A simple Tenax method to determine the chemical availability of sediment-sorbed organic compounds. Environ. Toxicol. Chem. 20: 706-711.

Jensen, J.-Folker-Hansen, P. (1995): Soil quality criteria for selected organic compounds. Danish Environmental Protection Agency. Working Report. No. 47.

Jones, K. C.-Alcock, R. E.-Johnson, D. L.-Northcott, G. L.-Semple, K. T.-Woolgar, P. J. (1996): Organic chemicals in contaminated land: analysis, significance and research priorities. Land Cohtam \& Reclam. 4: 189-197.

Karickhoff, S. (1984): Organic pollutant sorption in aquatic systems. J. Hydraulic Engin. 110: 707-735.

Kelsey, J. W.-Kottler, B. D.-Alexander, M. (1997): Selective chemical extractants to predict bioavailability of soil-aged organic chemicals. Environ. Sci. Technol. 31: 214-217.

Maliszewska-Kordybach, B. (1995): The persistence of carcinogenic micropollutant - pyrene - in the soil of the different organic matter content. Arch. Ochr. Srodow. 2: 183-190.

Maliszewska-Kordybach, B. (1998): The relation between the properties of PAH and the rate of their disappearance from different soils. Toxicol. Environ. Chem. 66: 45-50.

Smreczak, B.-Harmsen, J. (2001): PAH degradation in aerobic soils the role of bioavailability. Proceedings of the First European Bioremediation Conference. Chania. 67-70.
Smreczak, B.-Krektun, B.-Maliszewska-Kordybach, B.-KlimkowiczPawlas, A. (2005): Preliminary investigation on determination of PAH bioavailable fraction in freshly contaminated soil. Book of abstracts of International Workshop "Fate and Impact of Persistent Pollutants in Agroecosystems". 10-12 March 2005. Pulawy. Poland. 56.

Smreczak, B.-Maliszewska-Kordybach, B.-Krektun, B.- Janusaauskaite, D. (2005): Relationship between the content of chemically determined bioavailable fraction of phenanthrene and its ecotoxic activity in soils - preliminary investigations. Brno. Czech Republic. September 5-7. the SECOTOX world congress and RECETOX conference. Brno. 39.

Smreczak, B.-Maliszewska-Kordybach, B. (2004): Wstepne badania nad oznaczaniem potencjalnie biodostepnych frakcji wielopierscieniowych wenglowodorow aromatycznych ( WWA) w glebach zanieczyszczonych tymi zwiazkami. Archiwum ochrony srodowiska. 29. 4: 41-50.

Snitynskiy, V. V.-Krektun, B. V.-Maliszewska-Kordybach, B.Smreczak, B. (2008): Fundamental principles of PAHs bioavailability assessment by means of modern agrochemical methods. Proceedings "Genesis, geography and ecology of soils". Lviv. Publishing center Ivan Franko Lviv. National University. 496-503.

Sims, R. C.-Oveercash, M. R. (1983): Fate of polynuclear aromatic compounds (PNAs) in soil-plant systems. Residue Reviews. 88: $1-68$.

Wild, S. R.-Jones, K. C. (1992): Organic chemicals entering agricultural soils in sewage sludges: screening for their potential to transfer to crop plants and livestock. Sci. Total Environ. 119: 85-119.

Xing, B.-Pignatello, J. J. (1997): Dual-mode sorption of lowpolarity compounds in glassy polyvinyl chloride and soil organic matter. Environ. Sci. Technol. 31: 792-799. 